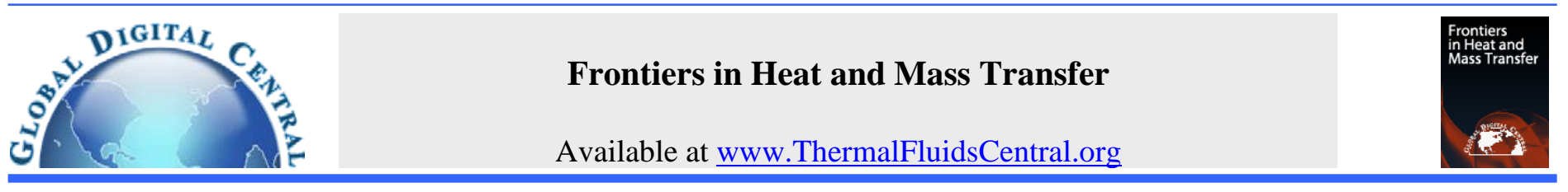

\title{
DATA CENTER ENERGY CONSERVATION BY HEAT PIPE BASED PRE- COOLER SYSTEM
}

\author{
Randeep Singh*, Masataka Mochizuki, Koichi Mashiko, Thang Nguyen* \\ Thermal Technology Business Unit, Fujikura Ltd,1-5-1, Kiba, Koto-Ku, Tokyo 135-8512, Japan
}

\begin{abstract}
In the present paper, data center energy conservation systems based on the heat pipe heat exchanger (HPHE) pre-cooler to downsize the chiller capacity and working time has analysed, designed and discussed. The proposed system utilizes thermal diode character of heat pipe to transfer waste heat from source (pre-cooler coolant) to ambient and have been analyzed as per metrological conditions in New York. HPHE Pre cooler with 118 heat pipes and designed for $30^{\circ} \mathrm{C}$ ambient temperature has been designed to effectively dissipate $30 \mathrm{~kW}$ or more datacenter heat throughout the year. The payback period of the HPHE Pre cooler is around 2.8 years. Proposed heat pipe based system utilize natural ambient cold energy and thus does not have running cost and related greenhouse gas emissions.

Keywords: datacenter cooling, pre-cooler, heat pipe, energy conservation, renewable energy, natural cold energy
\end{abstract}

\section{INTRODUCTION}

Electric power consumed by datacenter electronics and the cooling cost associated with them are massive. Cooling cost includes the capital and operation costs associated with the active and backup cooling equipment. It has been established from past trends and future forecasts that power consumed by datacenters is one of the major loads on the electric power station and it nearly doubles every five years (EPA, 2011, Kenneth, 2006). As an example, in 2006, power consumed by the datacenters in US was 61 billion $\mathrm{kWhr}$ which equals $1.5 \%$ of total power consumption of US and amounts to 4.5 billion dollar. For 2011, it has been estimated that this power consumption will increase to 100 billion kWhr with associated electrical cost of 7.4 billion dollar. Looking at more tangible comparison, power usage by US datacenters in 2011 is equivalent to power consumed by more than 11 million US houses or yearly electricity needs of whole Los Angeles city. The gravity of the problem is well understood from these massive power and cost figures. Out of the total power consumed by datacenter facility, cooling infrastructure takes up more than $50 \%$ electric load which is a huge percentage and therefore represents major cost overhead. Datacenters house mission critical computer systems and associated components for companies and organisations. Due to importance of the stored data and round clock demand on the availability of the datacenters, it is imperative to provide them with the backup power system to support computing equipment as well as their cooling systems. Due to the massive size of datacenters, it can be argued that cooling systems size and extent of sources (oil, gas or electricity) needed to power them will also be substantial. It should be noted that it is not only the running cost of the datacenter on the non-renewable electricity but also the environmental damage caused by them is considerable. Based on the above discussion, it can be concluded that propositions of energy conservation system for datacenters can save substantial electricity (thus running costs) and greenhouse gas emissions to the environment (Patel et al., 2002, Moore et al., 2004, Schmidt et al., 2005).
In the present paper, energy conservation systems based on heat pipes are proposed for datacenters as pre-cooler for datacenter chiller. The proposed system utilizes thermal diode characteristics of passively operating heat pipes to capture cold ambient energy for cooling purposes (Cabusao et al., 2010; Mochizuki et al., 2011; Singh et al., 2011, 2012; Wu et al., 2010, 2011)

\section{HEAT PIPE DIODE CHARACTER}

In the proposed pre-cooler system the heat pipes transfers the cold energy from the ambient to the coolant flowing inside the pre-cooler duct in realtime thereby cooling it by certain degrees, depending on the pre-cooler design and ambient air temperature, before it enters chiller to achieve the designed cold plate inlet temperature for datacenter servers.

The proposed systems utilize thermal diode characteristics of the wickless heat pipe or thermosyphon to capture and utilize cold energy from the ambient for cooling datacenter coolant. Figure 1 depicts the working principle of the thermosyphon which can extract heat from the coolant flowing through the high temperature pre-cooler and dissipate it to low temperature ambient by means of continuous evaporationcondensation process. In other words, the thermosyphon can only transfer heat when operating in the bottom heat mode (evaporator below condenser). For higher ambient temperature i.e. top heat mode or evaporator above condenser configuration, there will not be any heat transfer from ambient to storage media other than negligible heat conducted along the thermosyphon tube wall. Heat pipe heat exchanger based on this principle can be used as daily based (night to day) or seasonal based (winter to summer) energy systems. In addition to this, storage media for such system can store cold energy in sensible (same phase) as well as latent (phase change) form. In the proposed systems, the heat pipe container is made from stainless steel, condenser fins from aluminum and R134a is used as the working fluid. Due to longer length of the evaporator, stainless steel mesh was used to provide uniform liquid distribution along complete length of the evaporator. Please note 
condenser length was longer than evaporator length due to lower condensation heat transfer coefficient.

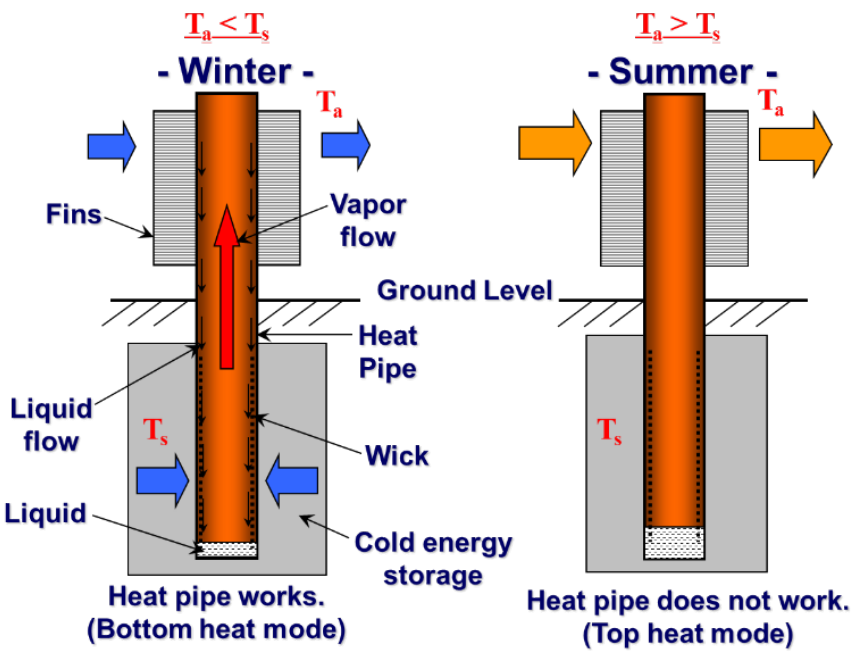

Fig. 1 Figure 1. Thermal diode character of heat pipe

\section{METROLOGICAL DATA}

Heat pipe heat exchanger system proposed in this study utilises natural cold energy from the ambient to dissipate heat from the datacentre servers. As a result, the yearly performance of the HPHE system will be dependent on the climatic conditions at the location. The metrological data on the yearly variation of the ambient air temperature and wind velocity is important to estimate the capability of the HPHE systems for the given location. In the present study, Poughkeepsie in New York with average yearly ambient temperature of $10 \mathrm{C}$ (Figure 2) and average yearly wind velocity of $1.7 \mathrm{~m} / \mathrm{s}$ has been chosen as the location of interest for studying the performance of the proposed system.

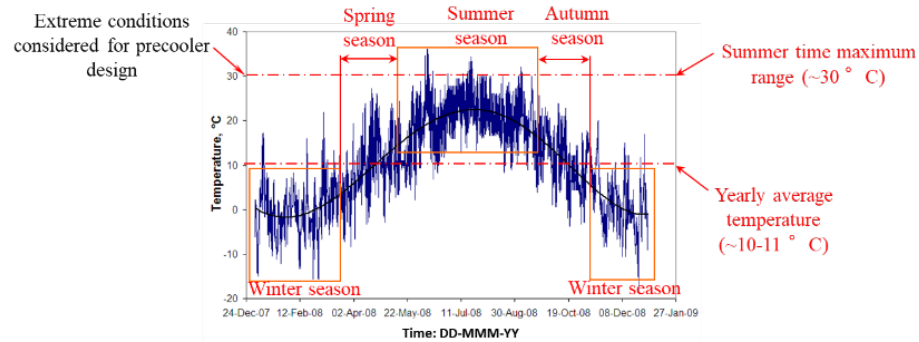

Fig. 2 Yearly temperature profile for Poughkeepsie

\section{HEAT PIPE PRE-COOLER ANALYSIS}

Heat pipe pre-cooler, as shown in Figure 3, was designed based on target cooling load to be handled by cooler as expressed by equation (1).

$Q_{c h}^{*}=Q_{d c}^{*}-Q_{p}^{*}$

where $Q_{p}^{*}$ is the pre-cooler designed load, in this case $30 \mathrm{~kW}, Q_{c h}^{*}$ is chiller loading and $Q_{d c}^{*}$ is total load on data center which is $60 \mathrm{~kW}$, for current investigation. Thermal resistance of individual heat pipe in the pre-cooler can be expressed by eq. (2).

$R_{t}=\frac{L M T D_{p}}{n_{t} Q_{h p}^{*}}$

where, LMTD for pre-cooler - $\mathrm{LMTD}_{\mathrm{p}}$, is expressed by eq. (3)
$L M T D_{p}=\frac{\left(T_{p-i}-T_{a}\right)-\left(T_{p-o}-T_{a}\right)}{\operatorname{Ln} \frac{\left(T_{p-i}-T_{a}\right)}{\left(T_{p-o}-T_{a}\right)}}$

In the case, water-glycol (50-50\%) is used as coolant. Inlet temperature for pre-cooler working fluid $\left(\mathrm{T}_{\mathrm{p}-\mathrm{i}}\right)$ is fixed to $51{ }^{\circ} \mathrm{C}$ by data center operating condition, outlet temperature $\left(\mathrm{T}_{\mathrm{p}-\mathrm{o}}\right)$ is considered w.r.t chiller loading considerations ( $43^{\circ} \mathrm{C}$ for current pre-cooler design). It should be noted that properties of the coolant was estimated from water and glycol properties for given temperature based on volumetric approach as per eq. (4).

$x_{w g}=0.5 x_{w}+0.5 x_{g}$

Ambient temperature is location dependent, and assumed $30{ }^{\circ} \mathrm{C}$ for current investigation. Number of heat pipe, nt, is function of fixed width, $\mathrm{W}_{\mathrm{d}}$, of heat pipe pre-cooler and placement of heat pipe in pre-cooler (staggered per Figure 3(c)).

$n_{t}=n_{\text {row }} n_{\text {col }}$

Here, $\mathrm{n}_{\text {col }}$ is fixed by cooler width, whereas $\mathrm{n}_{\text {row }}$ is calculated from eq. (2).

Total thermal resistance $-\mathrm{R}$, is presented by eq. (6).

$R_{t}=R_{w g-e w}+R_{e w}+R_{e v}+R_{c d}+R_{c w}+R_{c w-a}$

Heat pipe thermal resistances, $R_{e w}, R_{c w}$ - evaporator/condenser wall, $R_{e v}$, $\mathrm{R}_{\mathrm{cd}}$ - evaporation/condensation heat transfer coefficients, were calculated based on reference (Mochizuki et al., 2014). Convection thermal resistance from pre-cooler coolant to evaporator outer wall is given by:

$R_{w g-e w}=\frac{1}{\left(h_{w g} A_{e o}\right)}$

In this equation, hwg is calculated using:

$h_{w g}=\frac{N u_{D_{e o}} k_{w g}}{D_{e o}}$

Where, flow Nusselt number $\left(N u_{D_{e o}}\right)$ is calculated from eq. (9) (Incropera \& DeWitt, 2002)

$N u_{D_{e o}}=0.3+\frac{0.62 R e_{D_{e o}}^{1 / 2} P^{1 / 3}}{\left[1+(0.4 / P r)^{2 / 3}\right]^{1 / 4}}\left[1+\left(\frac{R e_{D_{e o}}}{282,000}\right)^{5 / 8}\right]^{4 / 5}$

Here,

$R e_{D_{e o}}=\frac{\rho_{w g} D_{e o} v_{\max }}{\mu_{w g}}$

$v_{\max }=\frac{v_{m} W_{d}}{\left(n_{c o l}+1\right) W_{f w}}$

$v_{m}=\frac{m_{w g}^{*}}{A_{d} \rho_{w g}}$

$A_{d}=W_{d} H_{e}$

Mass flow rate of the coolant is calculated from eq. (14) below:

$m_{w g}^{*}=\frac{Q_{p}^{*}}{C_{p_{w g}}\left(T_{p-i}-T_{p-o}\right)}$

Thermal resistance from condenser wall to ambient (i.e. fin stack) was calculated using eq. (15). 


$$
R_{c w-a}=\frac{1}{\left(h_{a} \eta_{f s} A_{f o}\right)}
$$

where, air side convection heat transfer coefficient $-h_{a}$, is calculated by similar approach as coolant side convection coefficient $\left(\mathrm{h}_{\mathrm{wg}}\right)$ as outlined by eq. (8).

In order to calculate fin stack efficiency, $\eta_{f s}$, below methodology was used.

$\eta_{f s}=\left(1-\frac{N_{f} A_{f}}{A_{f o}}\left(1-\eta_{f}\right)\right)$

where,

$\eta_{f}=\frac{\operatorname{Tanh}\left(z L_{f}\right)}{z L_{f}}$

$z=\sqrt{\frac{h_{a} P_{f}}{k_{f} A_{f c}}}$

Number of heat pipe row, $\mathrm{n}_{\text {row }}$, per equation (5) dictate the length of pre-cooler, under given design conditions.

For variable ambient temperature $-\mathrm{T}_{\mathrm{a}}$, heat pipe pre-cooler effectiveness can be calculated as:

$\varepsilon_{P}=\frac{\left(T_{p-i}-T_{p-o}\right)}{\left(T_{p-i}-T_{a}\right)}$

Similarly, for variable pre-cooler outlet temperature, which is direct indication for pre-cooler load, the variations in heating effectiveness of heat pipe heat exchanger can be calculated from eq. (19).

For the given metrological conditions, as shown in Figure 2, the precooler actual load handling on daily, monthly and yearly basis can be calculated from eq. (1), which will provide indications on chiller power consumption or loading factor from eq. (20).

$\delta_{c h}=\frac{Q_{c h}^{*}}{Q_{d c}^{*}} \times 100$

\section{HEAT PIPE PRE-COOLER DESIGN \& PERFORMANCE ESTIMATION}

Figure 3 (a) shows the schematic of the datacenter facility with the precooler integrated between the datacenter racks and chiller. The coolant used to extract heat from the datacenter server is mixture of water and propylene glycol (50-50\% by volume). For the $120 \mathrm{~kW}$ datacenter, the pre-cooler has been designed to handle one-fourth (30 kW) of the heat load and designed for $30{ }^{\circ} \mathrm{C}$ ambient temperature which represents the upper limit of summer time temperature for POU, New York.

HPHE Pre-cooler has 118 heat pipes with $38 \%$ heating effectiveness for coolant inlet and outlet temperatures of $51^{\circ} \mathrm{C}$ and $43^{\circ} \mathrm{C}$ respectively. The evaporator and condenser length of the heat pipes is 1 and $2 \mathrm{~m}$ respectively with $90 \mathrm{~mm}(\mathrm{~L}) \times 90 \mathrm{~mm}(\mathrm{~W}) \times 0.5 \mathrm{~mm}(\mathrm{~T})$ fins on condenser side. Figure 3(b) \& (c) presents the air (cross flow) and coolant flow directions through the HPHE pre-cooler. The air velocity of $1.8 \mathrm{~m} / \mathrm{s}$ provides forced air cooling to the condenser portion. As the fan velocity is very close to yearly average wind speed $(1.7 \mathrm{~m} / \mathrm{s})$ therefore power consumed by the air movers will be very low.

The size and performance of the HPHE pre-cooler is very dependent on the designed ambient air temperature (in this case $30^{\circ} \mathrm{C}$ ). Figure 4 (a) presents the effect of the ambient temperature on the HPHE size and effectiveness. It should be noted that the designed temperature is location dependent therefore to install the similar capacity heat exchanger at hotter location (e.g. Singapore), the size will be much larger. The size of the heat pipe heat exchanger system will also depends on the expected effectiveness from the system. Normally, for the heat pipe system, the effectiveness value less than or close to $50 \%$ is considered good, based on achieving payback time of HPHS system, to be within 5 years of system operating time. For high effectiveness, the system size and therefore cost is the prohibiting factors. Figure 4(b) presents the effectiveness and size variation of the HPHE for the range of the coolant outlet temperature. For the designed coolant outlet temperature of $43 \mathrm{C}$, the effectiveness of the pre-cooler with 118 heat pipes will be $38 \%$.

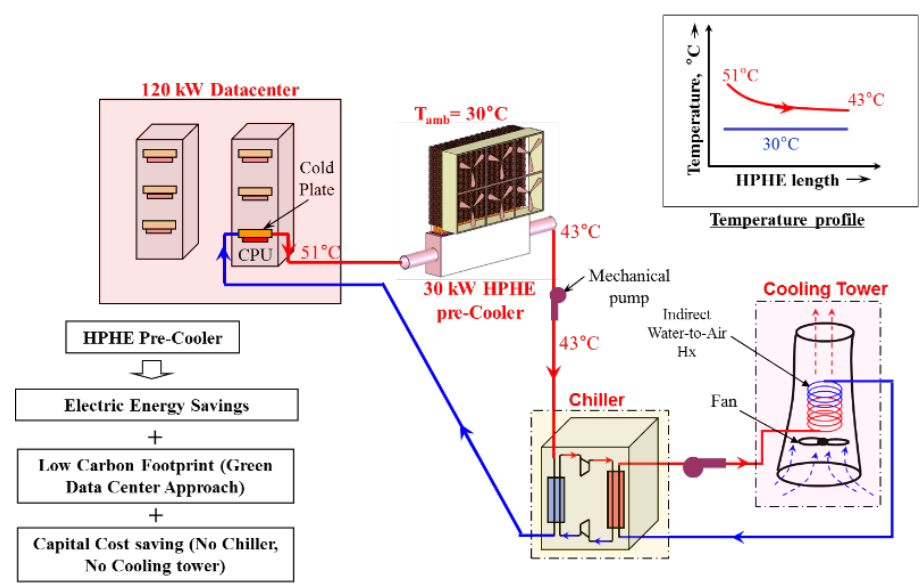

(a) Datacenter facility with HPHE pre-cooler

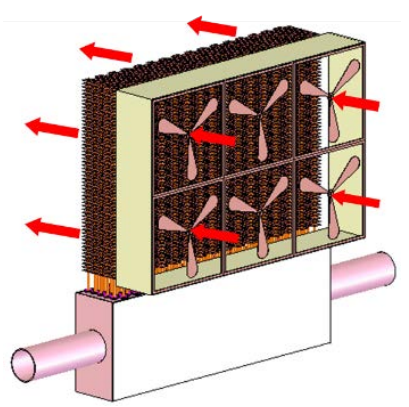

(b) Air flow pattern through HPHE pre-cooler condenser

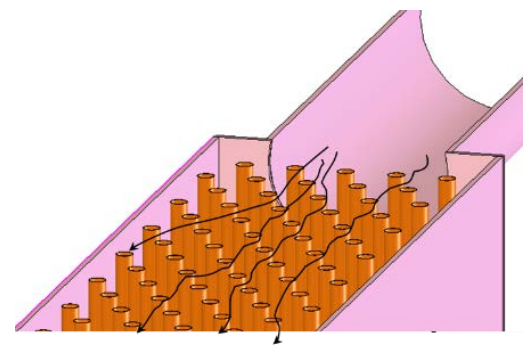

(c) Coolant flow inside the HPHE pre-cooler evaporator

Fig. 3 Details of heat pipe heat exchanger pre-cooler system

In Figure 5 (a), the yearly load handling capability of the HPHE precooler has been estimated. It is evident that the exchanger is able to dissipate the designed heat load (30 kW) through the year with capacity higher than designed value during most time of the year, except peak summer season. Figure 5 (b) presents the heat load handling capability of the pre-cooler for one of the hottest month in summer which shows that HPHE system is able to handle the designed heat load (30 kW) effectively. 


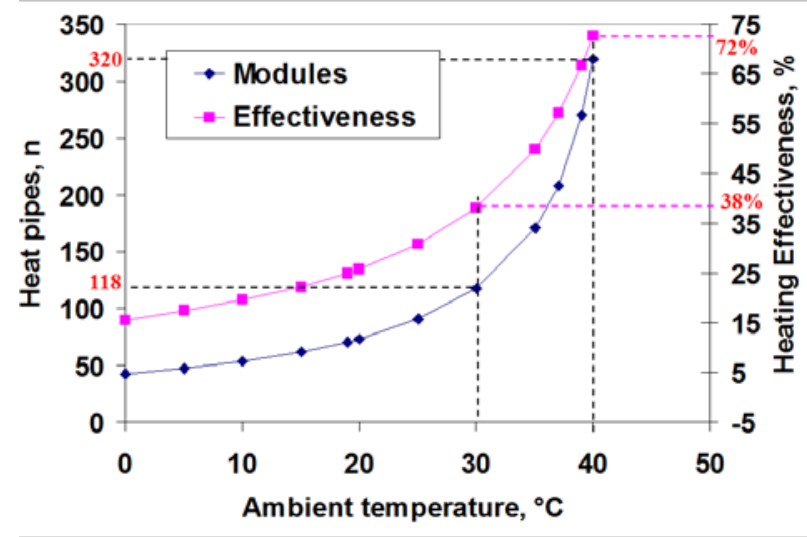

(a) Dependence on ambient air temperature

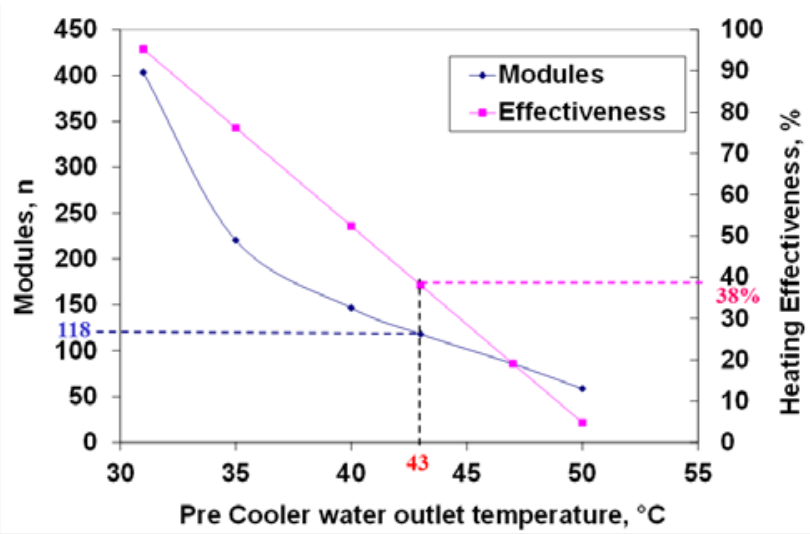

(b) Dependence on pre-cooler water outlet temperature

Fig. 4 HPHE Pre-cooler size and heating effectiveness

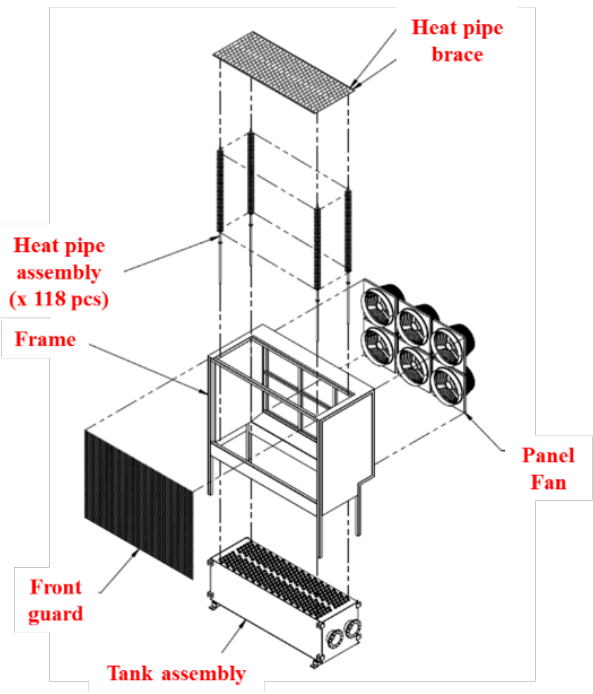

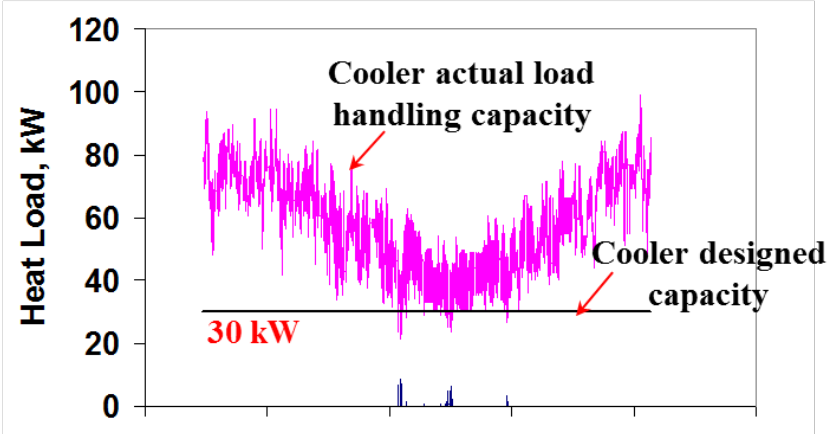

Nov-07 Feb-08 Jun-08 Sep-08 Dec-08 Mar-09

Time, mm-yy

(a) Yearly cooling demand

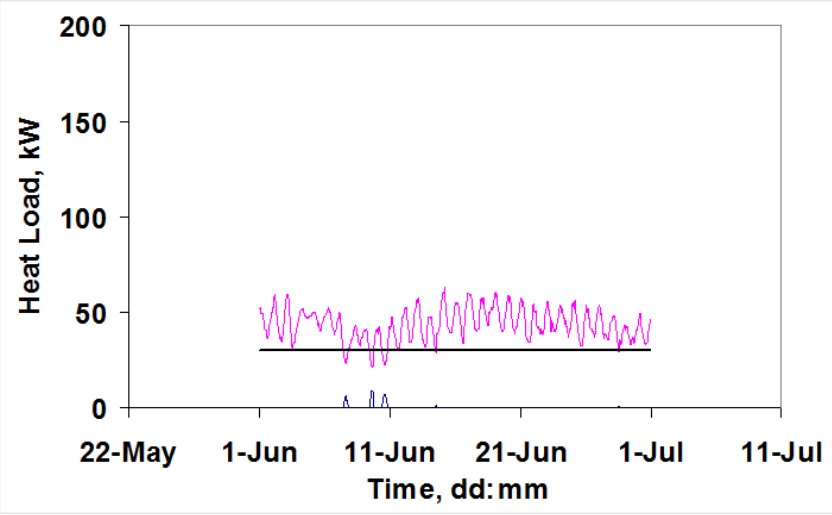

(b) Summer seasonal cooling demand

Fig. 5 Heat load handling capability of the heat pipe heat exchanger precooler

Fig. 6 HPHE Pre-cooler Assembly 


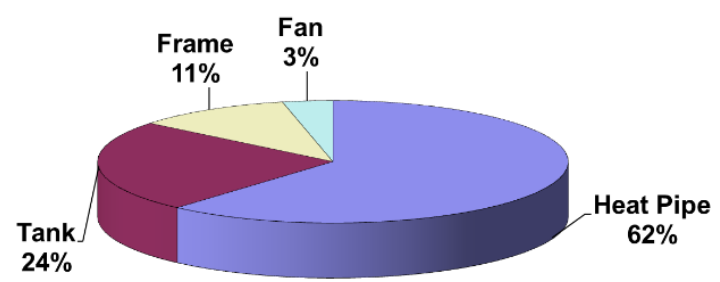

Fig. 7 HPHE cost analysis

Figure 6 presents the details of the heat pipe heat exchanger precooler designed on the basis of the presented analysis in section 4 . The main cost associated with the HPHE Pre-cooler is heat pipe and tank cost, as outlined in Figure 7.

\section{HEAT PIPE PRE-COOLER TEST RESULTS}

The novel concept of heat-pipe based cold energy capturing system was experimentally tested at Fujikura test facility at Aomori in Japan. Figure 8 (a) presents the details of the experimental test facility showing the condenser portion of heat pipe exposed to ambient with evaporator portion installed underground. The heat pipe module was made of stainless steel and R134a was used the working fluid. In order to minimize heat leaks from the ambient, the evaporator section of the thermosyphon along with the storage tank was installed underground level and the outer surface of the tank was insulated with thick layer of fibre glass insulation. The experiment was carried out for a winter period of 25 days during which the ambient temperature was below zero degrees Celsius. Figure 8(b) shows the results of the visual inspection that was done at the end of the test period which clearly validate the proposed concept. Based on the measured temperatures, it was estimated that approximately $113 \mathrm{~kg}$ of ice was produced during the test period.

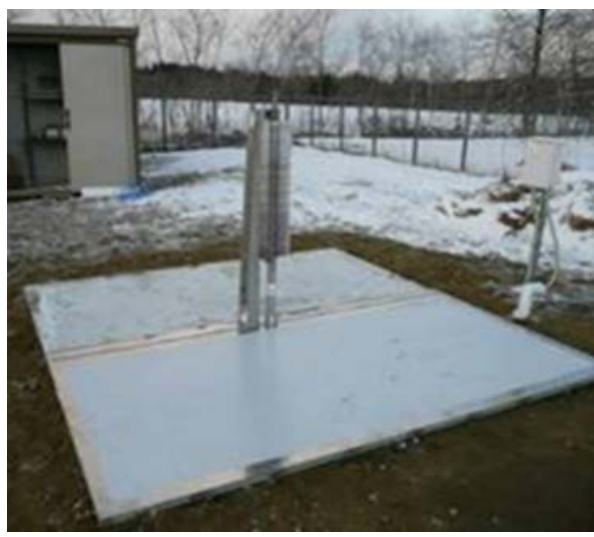

(a) Experimental set-up

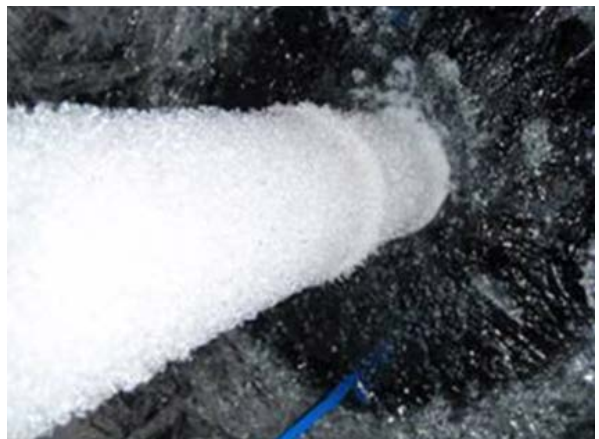

(b) Ice generation around the thermosyphon and inside ice storage tank

Fig. 8 Cold energy storage experiment using heat pipe heat exchanger
Table 1 presents the overall design summary with the seasonal heat load dissipation capability of the heat pipe heat exchanger. Based on the yearly performance of the pre-cooler, it is estimated that the payback period for the designed HPHE Pre-cooler will be around 2.8 years.

Table 1. Details of the heat pipe pre-cooler

\begin{tabular}{|c|c|}
\hline Parameter & Detail \\
\hline $\begin{array}{l}\text { Number of thermosyphon } \\
\text { modules }\end{array}$ & 118 (22 rows x 5 columns) \\
\hline \multirow[t]{2}{*}{$\begin{array}{l}\text { Thermosyphon } \\
\text { specifications }\end{array}$} & $\begin{array}{l}\text { Stainless steel body, Aluminium } \\
\text { Fins, R134a: working fluid }\end{array}$ \\
\hline & $\begin{array}{c}\text { Evaporator: } \mathrm{L}=1 \mathrm{~m}, \mathrm{OD} / \mathrm{ID}: \\
\text { 30/28 mm } \\
\text { Condenser: } \mathrm{L}=2 \mathrm{~m}, \mathrm{OD} / \mathrm{ID}: 30 / 28 \\
\mathrm{~mm} \\
\text { Fin: } 90 \mathrm{~mm} \times \mathbf{m} 90 \mathrm{~mm} \text { x } 0.5 \mathrm{~mm} \\
\text { (x267) }\end{array}$ \\
\hline $\begin{array}{l}\text { Cost of HPHE Pre-cooler } \\
\text { Unit }\end{array}$ & 60,808 \$ (for $30 \mathrm{~kW}$ data center) \\
\hline $\begin{array}{l}\text { Heat transfer capacity (in } \\
\text { winter: } 1^{\circ} \quad \mathrm{C} \text { average) }\end{array}$ & $\begin{array}{c}71 \mathrm{~kW}, 32^{\circ} \mathrm{C} \text { water outlet } \\
\text { temperature }\end{array}$ \\
\hline $\begin{array}{l}\text { Heat transfer capacity (in } \\
\text { Autumn \& Spring: } 10^{\circ} \mathrm{C} \\
\text { average) }\end{array}$ & $\begin{array}{c}58 \mathrm{~kW}, 35^{\circ} \mathrm{C} \text { water outlet } \\
\text { temperature }\end{array}$ \\
\hline $\begin{array}{l}\text { Heat transfer capacity (in } \\
\text { Summer: } 19^{\circ} \mathrm{C} \text { average) }\end{array}$ & $\begin{array}{c}45 \mathrm{~kW}, 38^{\circ} \mathrm{C} \text { water outlet } \\
\text { temperature }\end{array}$ \\
\hline $\begin{array}{l}\text { Total electric cost savings } \\
\text { per year }\end{array}$ & $21,101 \$$ \\
\hline Payback time on HPHE & 2.88 years \\
\hline
\end{tabular}

\section{CONCLUSIONS}

In the paper, heat pipe based pre-cooler system utilising natural cold energy from ambient to dissipate waste heat from datacenter servers has been proposed and analysed. The following conclusions are drawn for the system.

- $\quad$ HPHE Pre-cooler with 118 heat pipes and designed for $30{ }^{\circ} \mathrm{C}$ ambient temperature can effectively dissipate $30 \mathrm{~kW}$ datacenter heat for most of the year

- $\quad$ Size of the pre-cooler has strong dependence on the ambient temperature of the location.

- $\quad$ Payback period of the HPHE Pre-cooler is around $\sim 2.88$ years

- $\quad$ Proposed heat pipe based system utilizes natural ambient cold energy and therefore there is no running cost and no greenhouse gas emissions

\section{NOMENCLATURE}

A area, $\mathrm{m}^{2}$

$\mathrm{C}_{\mathrm{p}} \quad$ specific heat capacity, J/kg.K

D diameter, $\mathrm{m}$

h heat transfer coefficient, W/m2.K

$\mathrm{H}$ height, $\mathrm{m}$ 
$\mathrm{k}$ thermal conductivity, W/m.K

$\mathrm{L} \quad$ length, $\mathrm{m}$

m* mass flow rate, $\mathrm{kg} / \mathrm{s}$

$\mathrm{P} \quad$ perimeter, $\mathrm{m}$

Q* heat flow rate, $\mathrm{W}$

$\mathrm{R}$ thermal resistance, ${ }^{\circ} \mathrm{C} / \mathrm{W}$

$\mathrm{T}$ temperature, ${ }^{\circ} \mathrm{C}$

$\mathrm{v} \quad$ velocity, $\mathrm{m} / \mathrm{s}$

W width, $\mathrm{m}$

$\mathrm{x} \quad$ thermodynamic property

$\rho$ density, $\mathrm{kg} / \mathrm{m}^{3}$

$\mu \quad$ dynamic viscosity, Pa.s

$\mathrm{z} \quad$ parameter as defined by equation (18)

LMTD log mean temperature difference, ${ }^{\circ} \mathrm{C}$

\section{Subscripts}

a ambient air

cd condensation

ch chiller

cw condenser wall

col columns

d duct

dc data center

eo evaporator outer

ev evaporation

ew evaporator wall

$\mathrm{f} \quad$ fin

fc fin cross section

fo fin stack overall

fs fin stack

fw flow width

g glycol

hp heat pipe

i inlet

m mean

max maximum

o outlet

p pre-cooler

row rows

$\mathrm{t}$ total

w water

wg water-glycol

\section{Dimensionless Numbers}

$\mathrm{n}$ number of heat pipes

$\mathrm{N}$ number of fins

$\mathrm{Nu} \quad$ Nusselt Number

Pr Prandtl Number

Re Reynolds Number

$\varepsilon \quad$ effectiveness

$\eta \quad$ efficiency

$\delta \quad$ chiller load

\section{REFERENCES}

Cabusao, G., Mochizuki, M., Mashiko, K., Kobayashi, T., Singh, R., Nguyen, T., Wu, X.P., 2010, "Data center energy conservation utilizing a heat pipe based ice storage system,” CPMT Symposium Japan, Tokyo, pp. $1-4$.

Incropera FP., Dewitt DP, 2002, Fundamentals of heat and mass transfer, 5th ed. Wiley, Danvers

Kenneth G. Brill, 2006, 2005 - 2010 Heat Density Trends in Data Processing, Computer Systems, and Telecommunications Equipment:
Perspectives, Implications and the Current reality in Many Data Centers, 2000 - 2006, The Uptime Institute, version 2.1, 2006.

Mochizuki, M., Nguyen, T., Mashiko, K., Saito, Y., Wu, X.P., Nguyen, Ti., Wuttijumnong, V., Singh, R., 2011, Contribution of heat pipe to the energy conservation of data center and cloud computers, InterPACK Portland, Oregon, USA, CD ROMS051024, The Japan Society of Mechanical Engineers 2011 annual conference, 11 - 14, September, 2011, Tokyo, Japan, CD ROM

Mochizuki, M., Singh, R., Nguyen, T., Nguyen, Ti., 2014, "Heat Pipe Based Passive Emergency Core Cooling System for Safe Shutdown of Nuclear Power Reactor,” Applied Thermal Engineering, 73(1), pp. 699 706.

https://doi.org/10.1016/j.applthermaleng.2014.07.004

Moore J, Sharma R, Shih R, Chase J, Patel C and Ranganathan P., 2004, Going beyond CPUs: The potential for temperature-aware data centers. In Proceedings of the first workshop on temperature-aware computer system.

Patel CD, Sharma R, Bash CE, Beitelmal A., 2002, "Thermal Considerations in Cooling Large Scale High Compute Density Data Centers," Proceedings of 2002 InterSociety Conference on Thermal Phenomena, IEEE.

Schmidt R, Iyengar M, Steffes J, Lund V., 2009, "Co-generation- Grid Independent Power and Cooling for a Data Center,” Proceedings of the ASME 2009 InterPACK Conference, IPACK2009, San Francisco, USA.

Singh R. Mochizuki, M., Mashiko, K, Nguyen, T., 2011, “Heat Pipe Based Cold Energy Storage Systems for Datacenter Energy Conservation,” Energy, 36(5), pp. 2802 - 2811 https://doi.org/10.1016/j.energy.2011.02.021

Singh, R., Mochizuki, M., Mashiko, K., Nguyen, T., Wu, X.P., Wuttijumnong, V., 2011, "Datacenter Backup Cooling System Using Heat-Pipe Based Ice-Storage," The 48th National Heat Transfer Symposium, Okayama, Japan

Singh, R., Mochizuki, M., Nguyen, T., Saito, Y., Goto, K., Mashiko, K., 2012, “Loop Heat Pipe for Datacenter Thermal Control,” Paper no. G060041 , The Japan Society of Mechanical Engineers 2012 Annual Conference, Kanazawa, Japan, CD ROM

US Environmental Protection Agency (2011, March 25), Energy Star [Online] Available: http://www.energystar.gov/index.cfm?c=prod_development.server_effi ciency

Wu, X.P., Mochizuki, M., Mashiko, K., Nguyen, T., Nguyen, Ti., Wuttijumnong, V., Cabsao, G., Singh, R., Akbarzadeh, A., 2010, "Data center energy conservation by heat pipe cold energy storage system," International Heat Transfer Conference, IHTC-14, August 8-13, 2010, Omni Shoreham Hotel, Washington DC, USA Paper No: IHTC14-23128,

Wu, X.P., Mochizuki, M., Mashiko, K., Nguyen, T., Wuttijumnong, V., Cabsao, G., Singh, R., Akbarzadeh, A., 2010, Energy Conservation Approach for Data Center Cooling Using Heat Pipe Based Cold Energy Storage System, 26th IEEE SEMI-THERM (Semiconductor Thermal Measurement and Management) Symposium, Santa Clara, CA, USA, February 21-25, 2010, pp. 115 - 122

Wu, X.P., Mochizuki, M., Mashiko, K., Nguyen, T., Nguyen, Ti., Wuttijumnong, V., Cabusao, G., Singh, R., Akbarzadeh, A., 2011, "Cold energy storage systems using heat pipe Technology for cooling data centers," Frontiers in Heat Pipes, 2, 013005.

http://dx.doi.org/10.5098/fhp.v2.1.3005 